\title{
Adsorption thermodynamics and isosteric heat of adsorption of Thymol onto sodic, pillared and organic bentonite
}

\author{
University Mohamed 1st, Department of Chemistry, \\ LACPRENE, FSO, Oujda, Morocco
}

Elmiz Mohamed *, Essifi Kamal, Berraaouan Doha, Salhi Samira and Tahani Abdessalem

\begin{abstract}
We studied the temperature effects on thymol adsorption on sodium and modified clays from Nador, Morocco.

The clay samples used for these analyses were purified and modified by sodium, $\mathrm{Al}_{13}$ and Cetyl Pyridinium chloride before they were used as an adsorbent for the adsorption of thymol from aqueous solution in batch adsorption procedure. The adsorption experiments were carried out as a function of temperature. The adsorption was found to be strongly dependent on the temperature.

The Freundlich isotherm model showed an excellent fit to the equilibrium adsorption data. This equation indicates that the logarithm of $\mathrm{K}_{\mathrm{F}}$ is a linear function of temperature, and it decreases with temperature. The mean free energy (E) estimated from the Rankine (Calendar) modified model indicated that there is a significant relationship between adsorbed quantity and temperature and the primary mechanism governing the sorption process was a physisorption mechanism.

The Arrhenius and Eyring equations were used to obtain the activation parameters such as activation energy (Ea), and enthalpy $\left(\Delta \mathrm{H}^{\circ}\right)$, entropy $\left(\Delta \mathrm{S}^{\circ}\right)$ and free energy $\left(\Delta \mathrm{G}^{\circ}\right)$ of activation for the adsorption system. Thermodynamic studies suggested the spontaneous and endothermic nature of adsorption of thymol green by sodium and purified bentonite. The isosteric heat of adsorption $\left(\Delta \mathrm{H}_{\mathrm{X}}\right)$ was also determined from the equilibrium information using the Clausius-Clapeyron equation. $\Delta \mathrm{H}_{\mathrm{X}}$ increased with increase in surface loading, indicating some lateral interactions between the adsorbed molecules.
\end{abstract}

Keywords: Adsorption, clay, isosteric heat, temperature, physisorption.

\section{Introduction}

For many years, the clay materials have been used for adsorption of heavy metals, dye molecules, herbicides, anions such as nitrates, like phosphates and sulphates, or gas adsorption, like $\mathrm{SO}_{2}$. In industry, these materials are also used as a catalyst in organic syntheses or as an excipient in pharmacy. Their surface properties, like adsorption capacities, greatly govern the application of clay materials, surface charges, large surface area, and charge density.

The type of exchangeable cations, hydroxyl groups on the edges, silanol groups of the crystalline defects or broken surfaces and Lewis and Brönsted acidity The quality of a bentonite that refers to the performance of the material in its different applications depends mostly on the quality and quantity of the smectite, which the most common mineral is montmorillonite. Therefore, the isolation of some smectite group minerals from bentonites is of excellent importance ${ }^{1-5}$.

*Corresponding author: Elmiz Mohamed

Email address: Elmiz.mohamed@gmail.com

DOI: http://dx.doi.org/10.13171/mjc8619080210em
The Adsorption has attracted considerable interest in recent years as a wastewater treatment process. Equilibrium adsorption isotherms and isosteric enthalpy are the basic requirements for the characterization and development of adsorbents and the optimization of the sorption process. The isosteric heat of adsorption is a critical design variable in estimating the performance of an adsorptive separation process ${ }^{6}$. The heat of adsorption can be a strong and complex function of the adsorbate loading when the adsorbent is energetically heterogeneous. Generally, isosteric sorption enthalpy varies with the change in adsorption loading when organic compounds are adsorbed onto adsorbents ${ }^{7}$. It also gives some indication about the surface energetic heterogeneity ${ }^{8}$.

The complexity of the adsorption phenomena occurring at the liquid/solid interfaces has led to a few investigations on the subject matter ${ }^{9}$.

These properties may alter its antimicrobial efficacy and limit its application as a food antimicrobial agent ${ }^{10}$. Several studies of

Received June 2, 2019

Accepted June 15, 2019

Published August 2, 2019 
encapsulation of thymol with different materials have been developed in these 5 years: as preparation of nano-bio-composite, antioxidant films based on poly (lactic acid), and thymol for active packaging ${ }^{11}$, antimicrobial activities of thymol zein loaded in nanoparticles, stabilized by sodium chloride doublelayer caseinate-chitosan. The adsorption of thymol on pyrite, and thymol adsorption of aqueous solution; Use granulated surfactant Initiated modification bentonite by packed column methods.

This work is the result of previews works carried out in 2013 and 2014, consists of studying the adsorption of thymol on purified sodium and modified clay (pillared clay). The results obtained showed that the adsorption depends on the initial concentration of the thymol. The maximum amounts of thymol adsorbed by Na-bentonite and $\mathrm{Al}_{13}$ clay (pillar clay) were $177 \mathrm{mg} / \mathrm{g}$ and $319 \mathrm{mg} / \mathrm{g}$, respectively.

For kinetics, adsorption is rapid, with $90 \%$ of thymol adsorbed in the first 10 minutes for pillared $\left(\mathrm{B}-\mathrm{Al}_{13}\right)$ while approximately 20 minutes are required for adsorption on purified and sodium-exchanged clay (B-Na). This difference in the equilibrium time is due to the nature of the interactions of each clay with the thymol and the rate of the surface disposed of each clay. The linear form of the Freundlich isotherm seems to produce a reasonable model for the adsorption of thymol on the three supports, which shows the presence of highly energetic sites where the thymol molecules have been adsorbed.

On the other hand, one of the essential parameters that must be known for the adsorption processes is the isosteric heat of sorption. It represents the energy released during the adsorption; during desorption, it symbolizes the energy needed to break or to create the intermolecular forces between the adsorbent molecules and the surface of the clay.

Although the influence of temperature on adsorption has been carefully studied, no universal law has yet been found. Indeed, bibliographical studies 12, 13 have shown that an increase in temperature can lead to either an increase or a decrease in the amount adsorbed. When the adsorption is exothermic, the adsorbed amount decreases as the temperature increases. On the contrary, when the adsorbed quantity increases with temperature, the adsorption is endothermic ${ }^{14}$.

The aim of this work is the study of adsorption isotherm of thymol on sodic, pillared and Organic bentonite (modified montmorillonite clay), for different temperatures, to describe curves by a suitable model and to calculate the isosteric heat of sorption. Besides, analytical models were used to adjust the experimental data and determine the net isosteric heat of sorption of the thymol at different temperature and clays.

In this work, we added the thymol adsorption study on organic clay, because the adsorption capacity can be caused by the adsorption due to the Van der Waals interactions between the thymol and the CPC hydrocarbon chains. ie, a surface different from other clays, as well as the hydrophobic property of the CPCmodified clay, promotes the adsorption of organic products and its low dispersion in the thymol solution, decreases the contact area with the solution.

\section{Materials and methods}

\section{Adsorbent and adsorbate.}

The clay samples used for these analyses were collected from Nador (North-East Morocco, North Africa). The bentonite was purified, and modified by sodium, $\mathrm{Al}_{13}$ and Cetyl Pyridinium chloride before it was used. Cetyl Pyridinium chloride used was from HIMEDA, > $98 \%$, pure, 100g. Thymol used was from Bernd Kraft $>99 \%$, pure, 500g. Aluminium chloride hexahydrate, pure, crystalline from Bernd Kraft $1 \mathrm{~kg}$.

\section{Purification and Preparation of Sodium Bentonite.}

In this method, a mass of $1 \mathrm{Kg}$ of raw clay was dispersed in 5 liters of distilled water with a solid/liquid ratio: $1 / 5$. The mixture was stirred for an hour, until the full homogenization suspension, followed by treatment by $\mathrm{HCl}(0.5 \mathrm{M})$ to remove carbonate. The resulting mixture was washed by $\mathrm{H}_{2} \mathrm{O}_{2}$ $(10 \%)$ in order to oxidize organic matter.

The resulting product was then extensively washed (6 times) with $\mathrm{NaCl} 1 \mathrm{M}$ and centrifuged to give saturated clays. The dark grey residue in the centrifuge tube was eliminated because it contained enriched fraction in impurity (quartz, cristobalite, feldspar ...)

The samples were then washed and dialyzed against distilled water until the conductivity in the dialysis bath was less than $2 \mu \mathrm{S} / \mathrm{cm}$. The granular fraction size $\leq 2 \mu \mathrm{m}$ were then obtained by accurate sedimentation. The air-dried clays were gently ground to give a powder of $\mathrm{Na}-\mathrm{B}$.

\section{Synthesis of Organo-clay (B-CPC) by Intercalation.}

A suitable amount of cationic surfactant (cetylpyridinium chloride HIMEDA $99 \%$ ) was dissolved in distilled water at a concentration of $1 \%$ of weight $(10 \mathrm{~g}$ surfactant in $1 \mathrm{~L}$ of distilled water) that was homogenized each time before use.

The modified organoclay was prepared as described by Srinivasan and Fogler (1990) ${ }^{15}$. Traditional organoclay was prepared by cation exchange. Na-montmorillonite was treated with cetylpyridinium chloride (CPC) for an amount equivalent to more than $100 \%$ of the CEC.

In order to prepare this support (CPCmontmorillonite) and homogenize it through mechanical stirring, $10 \mathrm{~g}$ of purified sodium clay with 
the solution of the surfactant was stirred for about 12 hours at room temperature. Montmorillonite resulting from cetyl-pyridinium chloride (CPCmontmorillonite) was washed several times with distilled water until the excess of surfactant, which appears in the form of foam, disappears, and then it was dried at $60^{\circ} \mathrm{C}$ and ground into a powder before use.

The unit cell formula was

$$
\left[\mathrm{Si}_{7,97} A l_{0,03}^{3+}\right]^{I V}\left[A l_{2,737}^{3+} \mathrm{Fe}_{0,221} \mathrm{Mg}_{1,157}\right]^{V I} \mathrm{O}_{20}(\mathrm{OH})_{4}\left(\mathrm{C}_{21} \mathrm{H}_{38} \mathrm{~N}\right)_{0,834}
$$

(The Roman numerals IV and VI on the cells designate the octahedral and tetrahedral sites respectively).

\section{Synthesis of Pillared Clay (B-Al-PILC) by $\mathrm{Al}_{13}$}

The pillaring solution containing $\left[\mathrm{Al}_{13} \mathrm{O}_{4}(\mathrm{OH})_{24}\right.$ $\left.\left(\mathrm{H}_{2} \mathrm{O}\right)_{12}\right]^{7+}$ cations was obtained by adding $250 \mathrm{ml}$ of $\mathrm{Al}_{13}(0.4 \mathrm{M})$ to $550 \mathrm{ml}$ of $\mathrm{NaOH}(0.4 \mathrm{M})$ (drop by drop flow). The final neutralization ratio, which is defined as $[\mathrm{OH}]_{\text {Tot }} /[\mathrm{Al}(\mathrm{III})]_{\text {Tot }}$ was 2.4 , and the solution was stirred for 12 hours at room temperature.

The resultant solution of $\mathrm{pH}=4.5$, was added to the clay suspension $2 \%\left(1 \mathrm{~g}\right.$ clay/100 $\left.\mathrm{ml} \mathrm{H}_{2} \mathrm{O}\right)$ and stirred for 6 hours at room temperature. The pillared clay form was then centrifuged, filtered and dried at $60{ }^{\circ} \mathrm{C}$ in air.

Calcination was performed at $350{ }^{\circ} \mathrm{C}$ for 6 hours. The degree of intercalation of the pillaring cations was determined by X-Ray Diffraction, by analysing the variations of $d$ (001) in oriented clay-aggregate ${ }^{16}$.

The resultant modified bentonite complexes were characterized using FTIR, with a combination of $\mathrm{XRD}$, and textural analysis.

\section{Characterization Methods.}

The natural samples purified and modified clay are subjected to analysis and identification (see previous work) 17-19 by X-ray diffraction (XRD), infrared spectroscopy (IR) and Thermal, textural and physicochemical analysis.

X-ray diffractograms were recorded in a Shimadzu XRD diffractometer D6000 stations working on the monochromatic copper K $\alpha 1$ radiation (1.54 $\AA$ ).

Infra-Red (I.R) spectra were acquired using a Shimadzu Fourier Transform spectrometer over a range varying from 400 to $4000 \mathrm{~cm}^{-1}$ with a resolution of $2 \mathrm{~cm}^{-1}$, and the samples were prepared in the form of a dispersion in a vial $\mathrm{KBr}(1 / 200$ by weight).

Thermal analysis was carried out in a SHIMADZU D6000 coupled to a DC ampler and temperature controller.

Data from DTA-TG were obtained in all cases at a heating rate of $5^{\circ} \mathrm{C} / \mathrm{min}$ between $30^{\circ} \mathrm{C}$ and $1000^{\circ} \mathrm{C}$ and under $\mathrm{N}_{2}$ atmosphere.

The textural characteristics of clays before and after modification were determined by two methods:
First, from $\mathrm{N}_{2}$ adsorption/desorption isotherms at $77^{\circ} \mathrm{K}$ using micrometric ASAP 2000 volumetric adsorption-desorption apparatus and surface Area and Pore Size Analyzer. The BET surface areas were calculated using the multi-point method for the use of relative pressure $\left(\mathrm{P} / \mathrm{P}_{0}\right)$ between 0.00095 and 0.9917 . Second, the total surface and external and internal surface areas were determined from the adsorption of ethylene glycol.

Adsorption isotherms, which represent the adsorbed amount versus the equilibrium concentration, have been identified for each clay and temperature ${ }^{17,18}$.

\section{Results and Discussion}

The study of the adsorption of thymol on the different types of clay, as a function of temperature, was conducted by experiments carried out in a temperature range of $10^{\circ} \mathrm{C}$. to $70^{\circ} \mathrm{C}$. The results obtained are illustrated in Figures 1, 2 and 3.

The maximum amounts of thymol adsorbed by sodium bentonite (B-Na), Al13 modified clay (pillar clay), and CPC-modified clay (organophilic clay) are respectively: $177 \mathrm{mg} / \mathrm{g}, 319 \mathrm{mg} / \mathrm{g}$ and $183 \mathrm{mg} / \mathrm{g}$.

For the studied clays (sodium pillared and organophilic clay), the thymol adsorption isotherms have a rising portion. This behavior is related to the weakly hydrophilic nature of the molecule that promotes hydrophobic interactions with the solid. This affinity for the active sites of the solid favors a monolayer adsorption.

The high adsorption capacity of Na-bentonite and pillared clay may be due to adsorption by Van DerWalls interactions and the hydrogen bonds between thymol and pillared clay, and also by interactions between the negative $\mathrm{Si}_{-} \mathrm{O}^{-}$charge for sodium bentonite and the partial positive hydrogen charge of the Thymol $(\mathrm{OH})$ function ${ }^{20}$. 


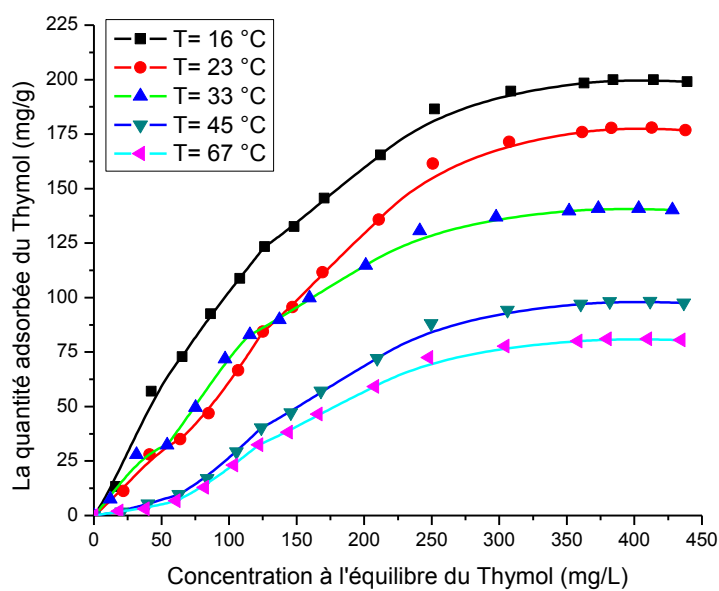

Figure 1. Evolution of the adsorbed quantity of thymol on sodium clay with temperature

The low solubility of the thymol molecules at low temperatures favors the phenomenon of adsorption of the molecule on the different types of clays studied.

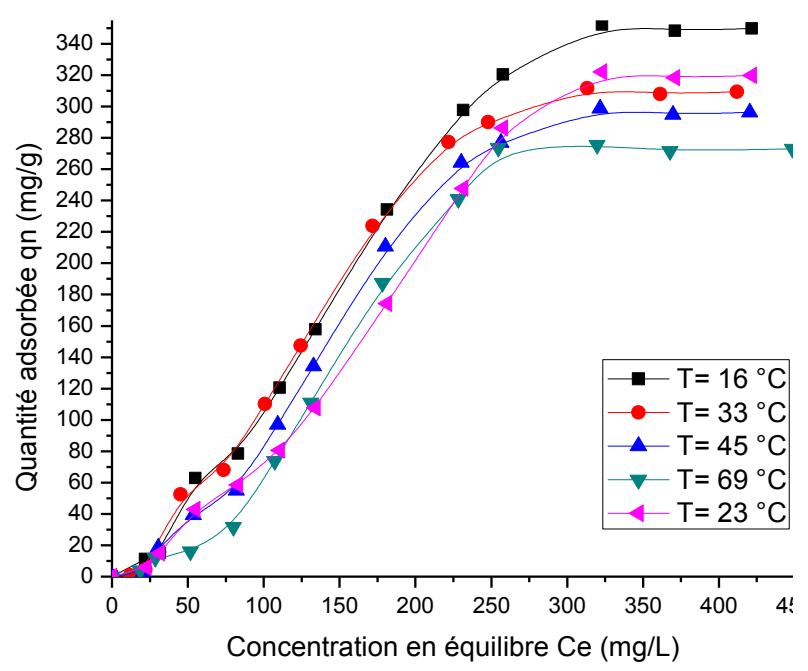

Figure 2. Evolution of the adsorbed quantity of thymol by pillar clay with temperature

\section{Determination of the thermodynamic parameters of adsorption}

The thermodynamic parameters of the thymol adsorption on the various clays that are: the enthalpy variation $\left(\Delta \mathrm{H}^{\circ}\right)$, the Gibbs free energy variation $\left(\Delta G^{\circ}\right)$ and the entropy variation $\left(\Delta S^{\circ}\right)$ can be calculated from the change in maximum adsorption when temperature $(\mathrm{T})$ varies using the following basic thermodynamic equations 21,22 . These values represent the thermodynamic magnitudes of adsorption.

$\Delta S^{\mathrm{D}}=\frac{\Delta H^{\mathrm{a}} \mathrm{ads}}{T}-\frac{\Delta G^{\mathrm{Q}}}{T}$

$\operatorname{Ln} K_{\text {ads }}=-\frac{\Delta G^{\mathrm{a}}}{R \times T}$

Equation 1

Equation 2

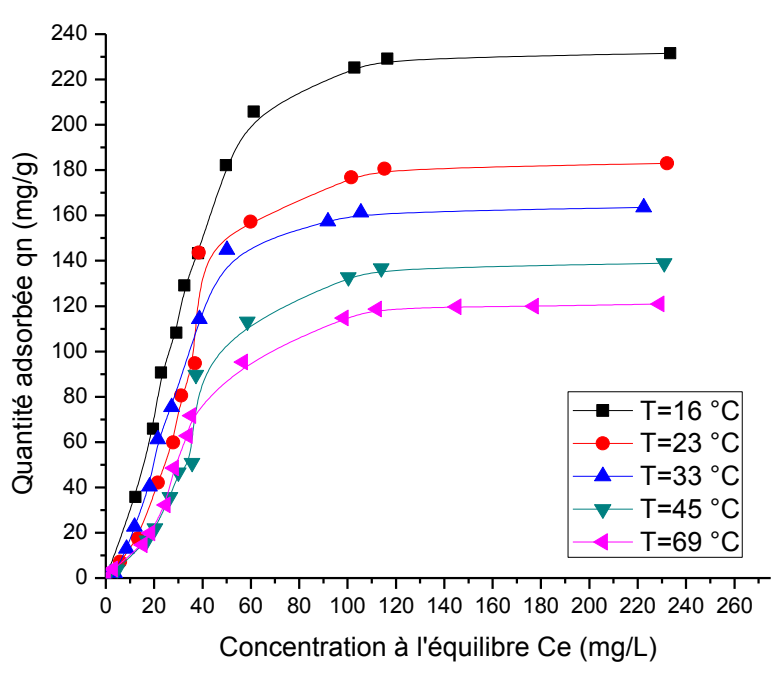

Figure 3. Evolution of the Adsorbed Amount of Thymol by CPC-Modified Clay with Temperature

$\operatorname{Ln} K_{a d s}=\frac{\Delta S^{\square}}{R}-\frac{\Delta H^{\square}{ }_{a d s}}{R \times T}$ Equation 3

$K_{a d s}=\frac{\left(q_{e} \times \frac{m}{V}\right)}{\left[C_{0}-\left(q_{e} \times \frac{m}{V}\right)\right]}$

Equation 4

According to the Equation 4, the mean value of the enthalpy change accompanying thymol adsorption on clays in the temperature range studied can be determined graphically by plotting LnKF versus $1 / \mathrm{T}$ using the Least-squares analysis shown in Figure 4. This average enthalpy change can be determined from the slope of the straight line. The variation of Gibbs energy and entropy as a function of temperature can be calculated using Equation 2 and Equation 3, respectively, the results obtained are given in Table 1. 
Table 1. The thermodynamic parameters of thymol adsorption on the studied clays.

\begin{tabular}{|c|c|c|c|c|}
\hline The studied clays & $\mathrm{T}\left({ }^{\circ} \mathrm{K}\right)$ & $\begin{array}{c}\Delta \mathrm{H}^{\circ} \\
(\mathrm{Kj} / \mathrm{mol})\end{array}$ & $\begin{array}{c}\Delta \mathrm{G}^{\circ} \\
(\mathrm{Kj} / \mathrm{mol})\end{array}$ & $\begin{array}{c}\Delta \mathrm{S}^{\circ} \\
(\mathrm{Kj} / \mathrm{mol})\end{array}$ \\
\hline \multirow[t]{5}{*}{ Sodium Clay B-Na } & 289,15 & \multirow[t]{5}{*}{$-2,499$} & $-1,2392$ & \multirow[t]{5}{*}{$-4,3568$} \\
\hline & 296,15 & & $-1,2087$ & \\
\hline & 306,15 & & $-1,1651$ & \\
\hline & 318,15 & & $-1,112$ & \\
\hline & 340,15 & & $-1,017$ & \\
\hline \multirow[t]{5}{*}{ Clay pillared by $\mathrm{Al}_{13}$} & 289,15 & \multirow[t]{5}{*}{$-2,876$} & $-1,8487$ & \multirow[t]{5}{*}{$-3,556$} \\
\hline & 296,15 & & $-1,8238$ & \\
\hline & 306,15 & & $-1,7882$ & \\
\hline & 318,15 & & $-1,7456$ & \\
\hline & 340,15 & & $-1,6673$ & \\
\hline \multirow[t]{5}{*}{ Organophilic clay B-CPC } & 289,15 & \multirow[t]{5}{*}{$-1,853$} & $-1,0408$ & \multirow[t]{5}{*}{$-2,811$} \\
\hline & 296,15 & & $-1,0211$ & \\
\hline & 306,15 & & $-0,993$ & \\
\hline & 318,15 & & $-0,9592$ & \\
\hline & 340,15 & & $-0,8974$ & \\
\hline
\end{tabular}

The results obtained (Table 1), show that the Gibbs free energy $\left(\Delta \mathrm{G}^{\circ}\right)$ is weak and negative, and its value decreases when the temperature increases. This indicates that the methods of adsorption of thymol by the clays studied could be slightly improved by the decrease of the temperature, globally the adsorption is spontaneous.

The values of the entropy variation $\left(\Delta \mathrm{S}^{\circ}\right)$ are negative and constant with the temperature, which shows that the adsorbed molecules in the case of Bentonite (B-CPC) are more disordered than those in the case of Bentonite-Na. The negative values of the enthalpy variation $\left(\Delta \mathrm{H}^{\circ}\right)$ show that the heats of adsorption of thymol by the studied clays are exothermic.

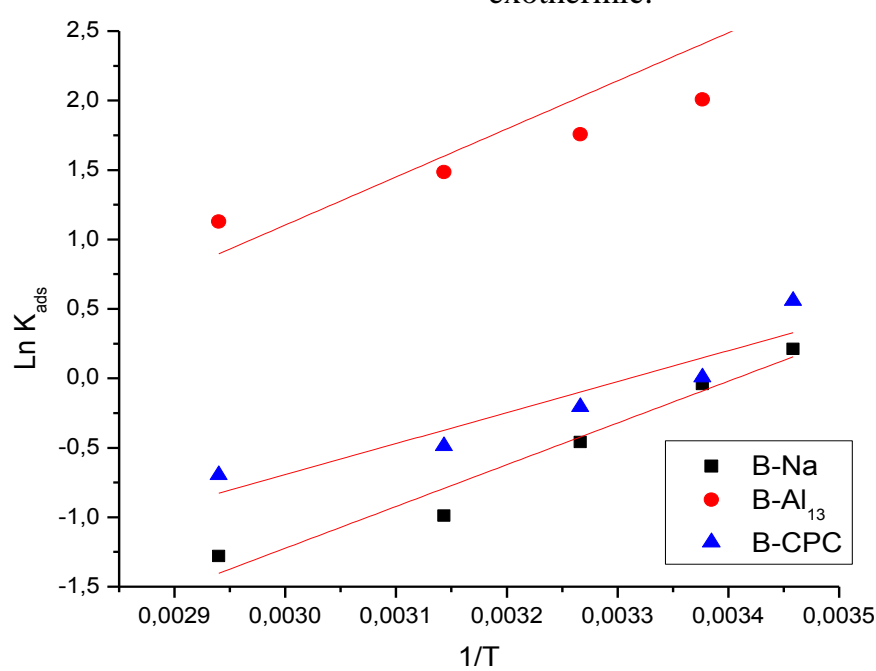

Figure 4. Determination of the enthalpy variation due to thymol adsorption on the studied clays

Adsorption $\Delta \mathrm{H}^{\circ}$ values are less than $80 \mathrm{kJmol}^{-1}$, indicating the physical nature of thymol adsorption on the different supports, physisorption was carried out with Van der Waals forces and by electrostatic interactions in the case of sodium bentonite.

Application of the Freundlich adsorption model at different temperatures

The $K_{F}$ and $n$ parameters of the Freundlich equation are often plotted against temperature. Their dependence on temperature is complex, and they should not be extrapolated outside their area of validity. The phenomenon of adsorption of thymol on the clays studied depends on the temperature and is inversely proportional to the temperature. This is considered as a specific trend rather than a general rule.

To calculate the dependence of $\mathrm{K}_{\mathrm{F}}$ and $\mathrm{n}$ with temperature, an approach developed by Urano et al. $(1981)^{23}$. They assumed that the surface of the solid is composed of sites with a surface adsorption energy distribution, which is defined as follows:

$\operatorname{Ln} K_{\text {ads }}=-\frac{\Delta G^{a}}{R \times T}$

Equation 5

The adsorption potential $\Delta \mathrm{G}^{\circ}$ corresponds to the energy required to bring the molecules of the aqueous phase with an equilibrium concentration $\mathrm{Ce}$ to be adsorbed on the surface and with a quantity of adsorption Qe. This means that the sites associated 
with $\Delta \mathrm{G}^{\circ}$ will have a potential to adsorb the molecules of the aqueous phase only if the adsorption potential of the molecule is lower than the adsorption potential of the active site, which will subsequently be occupied by an adsorbate molecule.

On the other hand, if the adsorption potential in the aqueous phase is higher, then the site will be unoccupied.

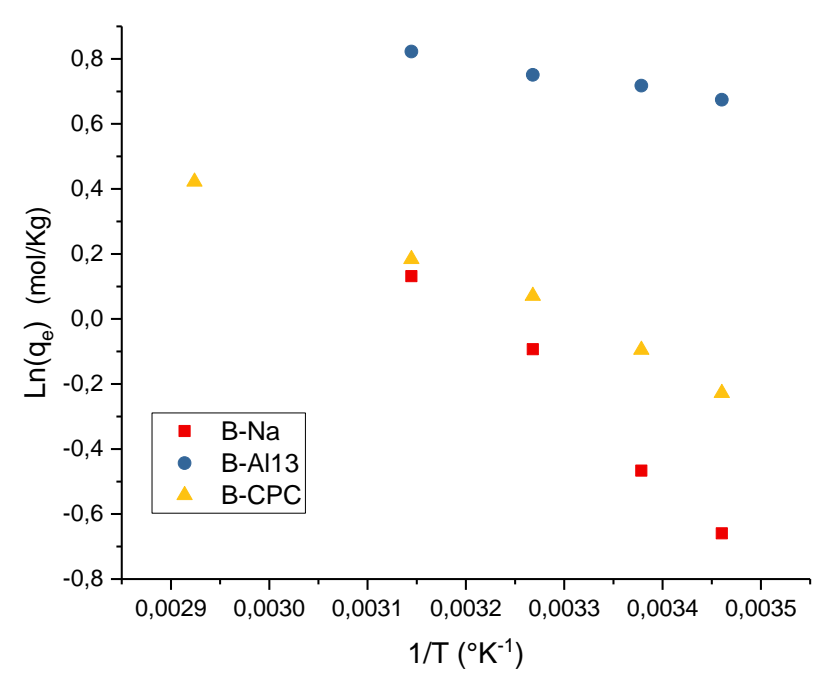

Therefore, if the surface has a surface adsorption potential of $F\left(\Delta \mathrm{G}^{\circ}\right)$ and the adsorbed amount having an adsorption potential between $\Delta \mathrm{G}^{\circ}$ and $\Delta \mathrm{G}^{\circ}+$ $\mathrm{d} \Delta \mathrm{G}^{\circ}$, the equation of isothermal adsorption is:

$q_{e}=\int_{\Delta G}^{\infty} F(\Delta G) \times \partial \Delta G$

Equation 6

Figure 5. Application of the modified Rankine model for the adsorption of thymol on the studied clays

To find the relation between maximum adsorbed quantity and temperature, we use the modified Rankine empirical relationship (Calendar) by plotting the adsorbed quantity $\mathrm{Ln}$ (qe) versus 1/T (Figure 5):

$\ln q_{e}=\alpha-\frac{\beta}{T}$

\section{Equation 7: Rankine (Calendar)} modified

The comparison of the regression coefficients shows that there is a significant relationship between adsorbed quantity and temperature. The equations of the lines drawn allow us to determine the " $\alpha$ " and " $\beta$ " constants of the model (Table 2).

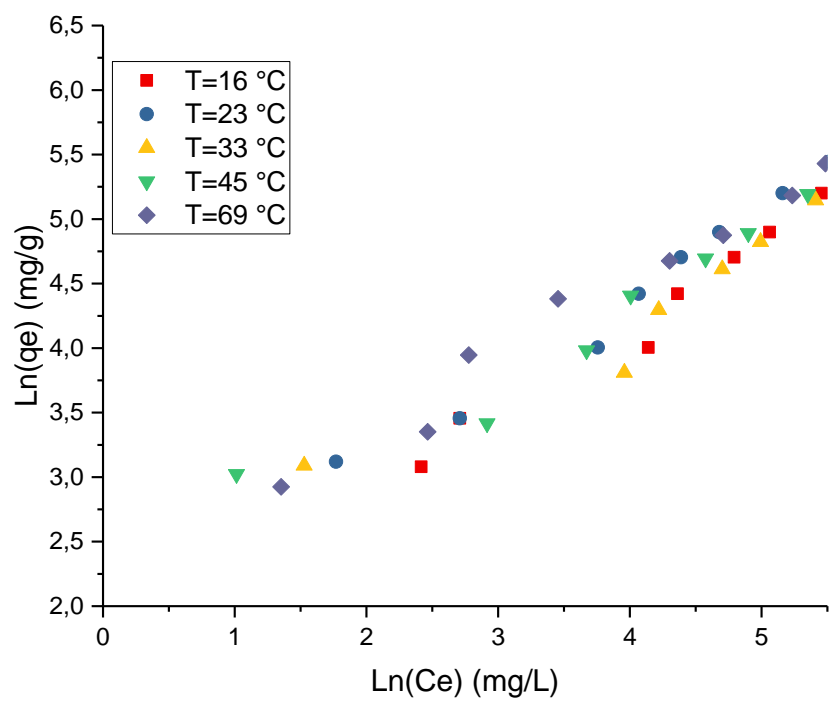

Figure 6. Application of the Freundlich model for different temperatures in the case of $\mathrm{B}-\mathrm{Al}_{13}$
If we take the logarithm of $\mathrm{K}_{\mathrm{F}}$ in the Freundlich equation and using the Clapeyron equation, we obtain the following equation for the temperature dependence of $\mathrm{LnK}_{\mathrm{F}}$ :

$$
\operatorname{Ln} K_{F}=\left[\operatorname{Ln}\left(\delta \times \Delta G_{0}\right)+\frac{\beta \times R}{\Delta G_{0}}\right]-\frac{\alpha \times R \times T}{\Delta G_{0}}
$$

Equation 8

This equation indicates that the logarithm of $\mathrm{K}_{\mathrm{F}}$ is a linear function of temperature, and decreases with temperature (Figure 6). 


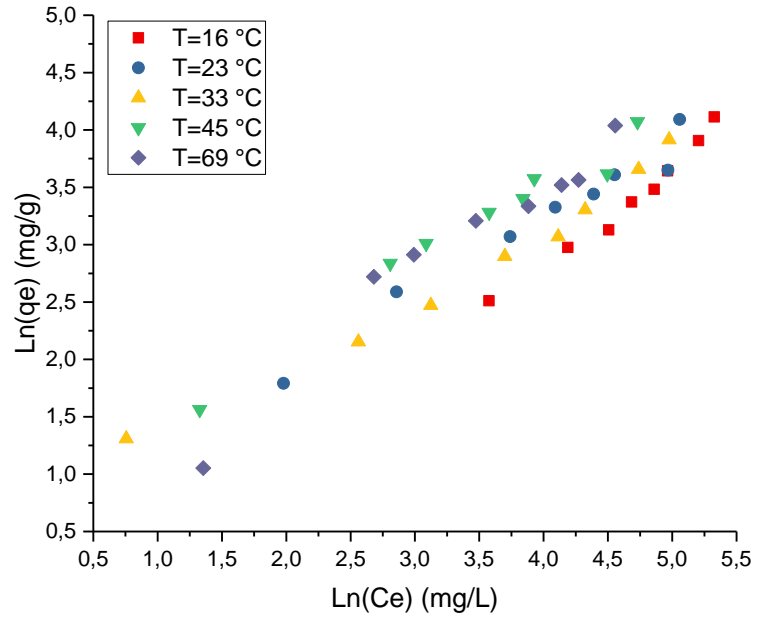

Figure 7. Application of the Freundlich model for different temperatures in the case of B-CPC

The following table shows the constants "K" and $n$

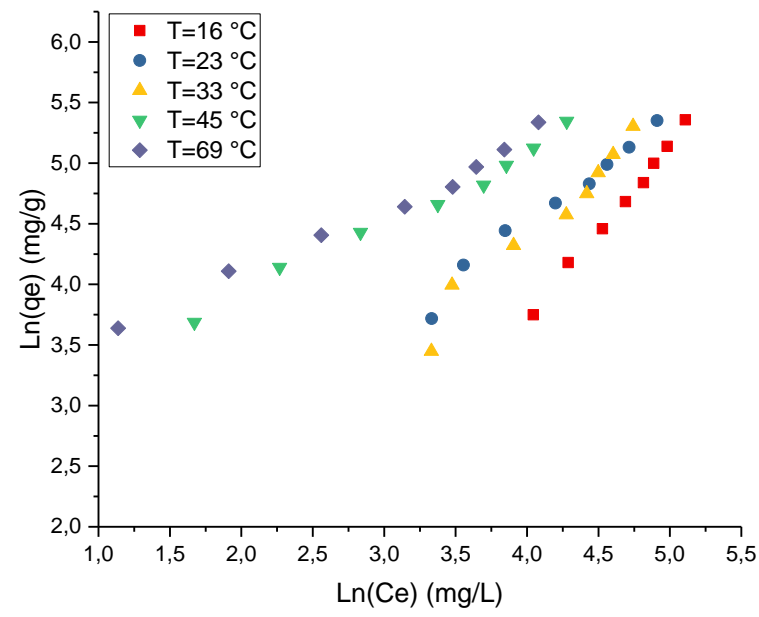

Figure 8. Application of the Freundlich model for different temperatures in the case of $\mathrm{B}-\mathrm{Na}$

calculated and used in the model of $\mathrm{LnK}_{\mathrm{F}} V s 1 / \mathrm{n}$.

Table 2. Freundlich model constants at different temperatures.

\begin{tabular}{|c|c|c|c|c|c|}
\hline Clays & T $\left({ }^{\circ} \mathrm{C}\right)$ & The Slope & The ordered at the origin & $\mathrm{K}_{\mathrm{F}}$ & $n$ \\
\hline Pillared Clay $\left(\mathrm{B}-\mathrm{Al}_{13}\right)$ & $\mathbf{2 8 9}$ & 1,3813 & $-1,7778$ & 0,169009 & 0,72395 \\
\hline & $\mathbf{2 9 6}$ & 1,4881 & $-2,5571$ & 0,077529 & 0,67199 \\
\hline & $\mathbf{3 0 6}$ & 1,5735 & $-2,7039$ & 0,066943 & 0,6355 \\
\hline & $\mathbf{3 1 8}$ & 1,6428 & $-3,2275$ & 0,039656 & 0,60871 \\
\hline & $\mathbf{3 4 2}$ & 1,6237 & $-3,3402$ & 0,035429 & 0,61587 \\
\hline Organophilic Clay & $\mathbf{2 8 9}$ & 1,0911 & 0,9631 & 2,619805 & 0,91650 \\
\hline (B-CPC) & $\mathbf{2 9 6}$ & 1,4634 & $-0,7232$ & 0,485197 & 0,68334 \\
\hline & $\mathbf{3 0 6}$ & 1,608 & $-1,0418$ & 0,352819 & 0,62189 \\
\hline & $\mathbf{3 1 8}$ & 1,4141 & $-1,0082$ & 0,364875 & 0,70716 \\
\hline & $\mathbf{3 4 2}$ & 1,5346 & $-1,3941$ & 0,248056 & 0,65163 \\
\hline & $\mathbf{2 8 9}$ & 0,8637 & 0,5449 & 1,724435 & 1,15780 \\
\hline & $\mathbf{2 9 6}$ & 1,0857 & 0,8733 & 2,394800 & 0,92106 \\
\hline & $\mathbf{3 0 6}$ & 0,9608 & 0,2314 & 1,260363 & 1,04079 \\
\hline & $\mathbf{3 1 8}$ & 1,6717 & 4,5168 & 91,54219 & 0,59819 \\
\hline & $\mathbf{3 4 2}$ & 1,8259 & 5,4731 & 238,1974 & 0,54767 \\
\hline
\end{tabular}

Thus, the functional form for describing the temperature dependence of $\mathrm{K}_{\mathrm{F}}$ is:

$$
L n K_{F}=\left[\operatorname{Ln}\left(\delta \times \Delta G_{0}\right)+\frac{\beta \times R}{\Delta G_{0}}\right]-\frac{\alpha}{n}
$$

Equation 9

With " $\alpha$ " and " $\beta$ " are determined from the modified Rankine equation (Table 3). See Figures 9, 10 and 11.

The results of Table 2 show that the constant " $\mathrm{K}_{\mathrm{F}}$ " interaction increases in parallel with the temperature in the case of sodium clay while the values of the constant $\mathrm{n}$ are more significant than 0.5 , which was characterized by relatively low adsorption. The same case is observed for organophilic clay but with values of $\mathrm{n}$ less than 0.5 , which characterizes favorable adsorption of thymol. For pillared clay, the $\mathrm{K}_{\mathrm{F}}$ values decrease by increasing the temperature with low values by comparing with the other supports, and with relatively constant values of $n$. In these cases, $n=0.6$ which characterizes moderate adsorption.

With $\mathrm{K}_{\mathrm{F}}$ represents the equilibrium constant that reflects surface-adsorbate interactions, the ratio $1 / \mathrm{n}$ indicates the intensity of adsorption. 


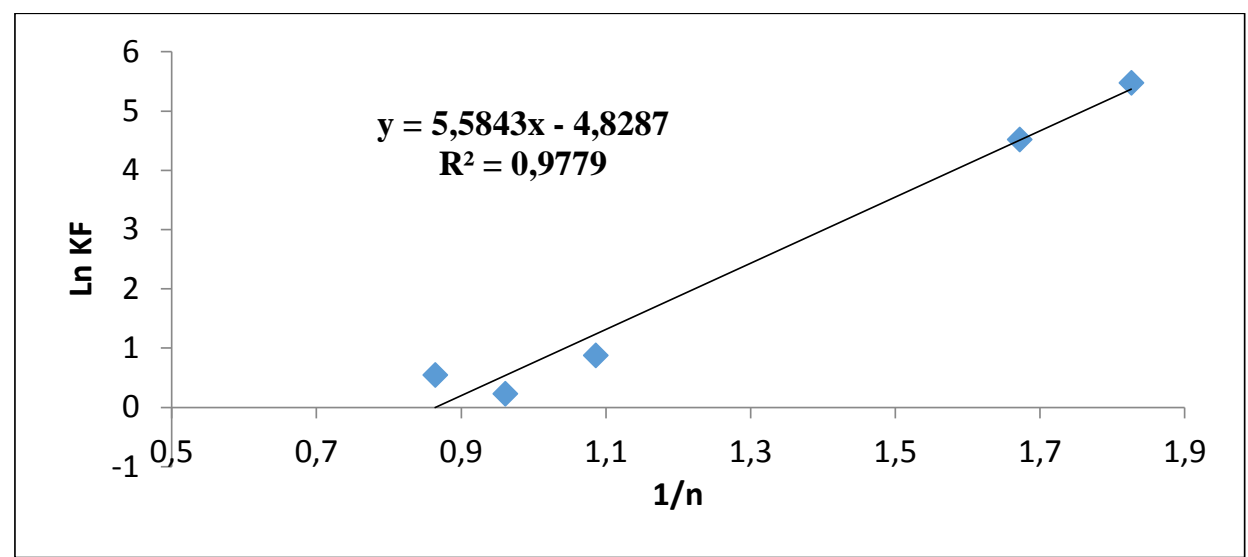

Figure 9. Application of the $\mathrm{LnK}_{\mathrm{F}}$ model as a function of $1 / \mathrm{n}$ for $\mathrm{B}-\mathrm{Na}$

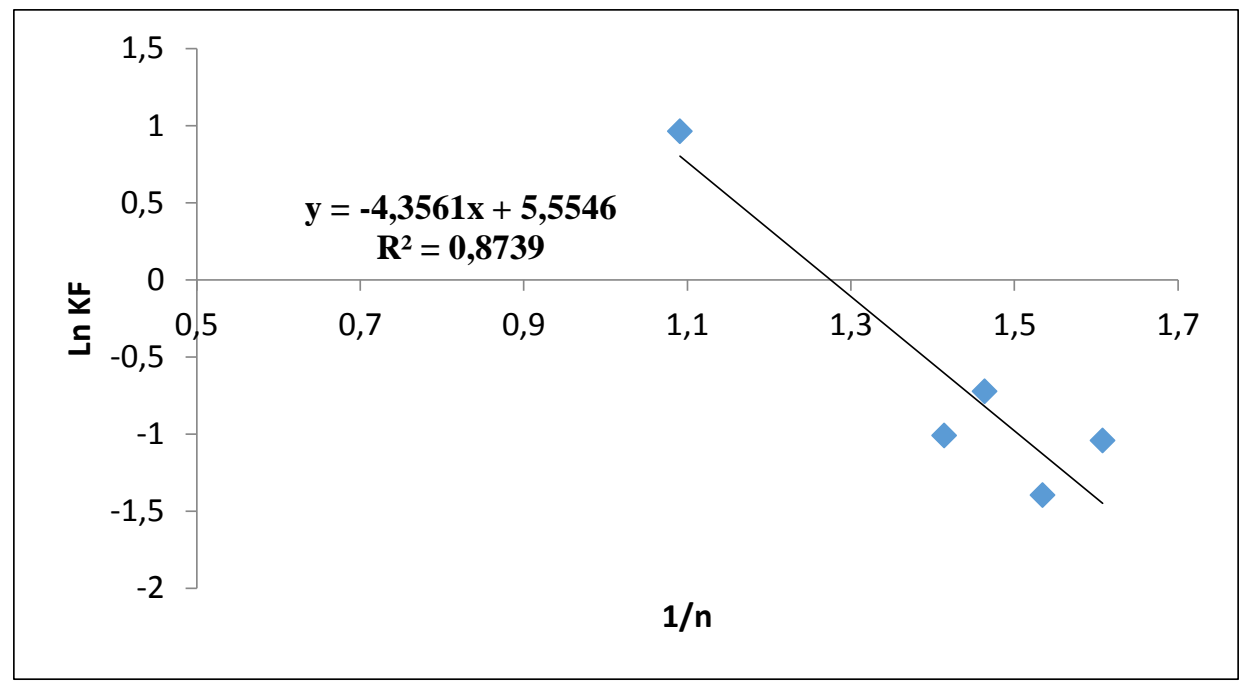

Figure 10. Application of the $\mathrm{LnK}_{\mathrm{F}}$ model according to $1 / \mathrm{n}$ for $\mathrm{B}-\mathrm{CPC}$

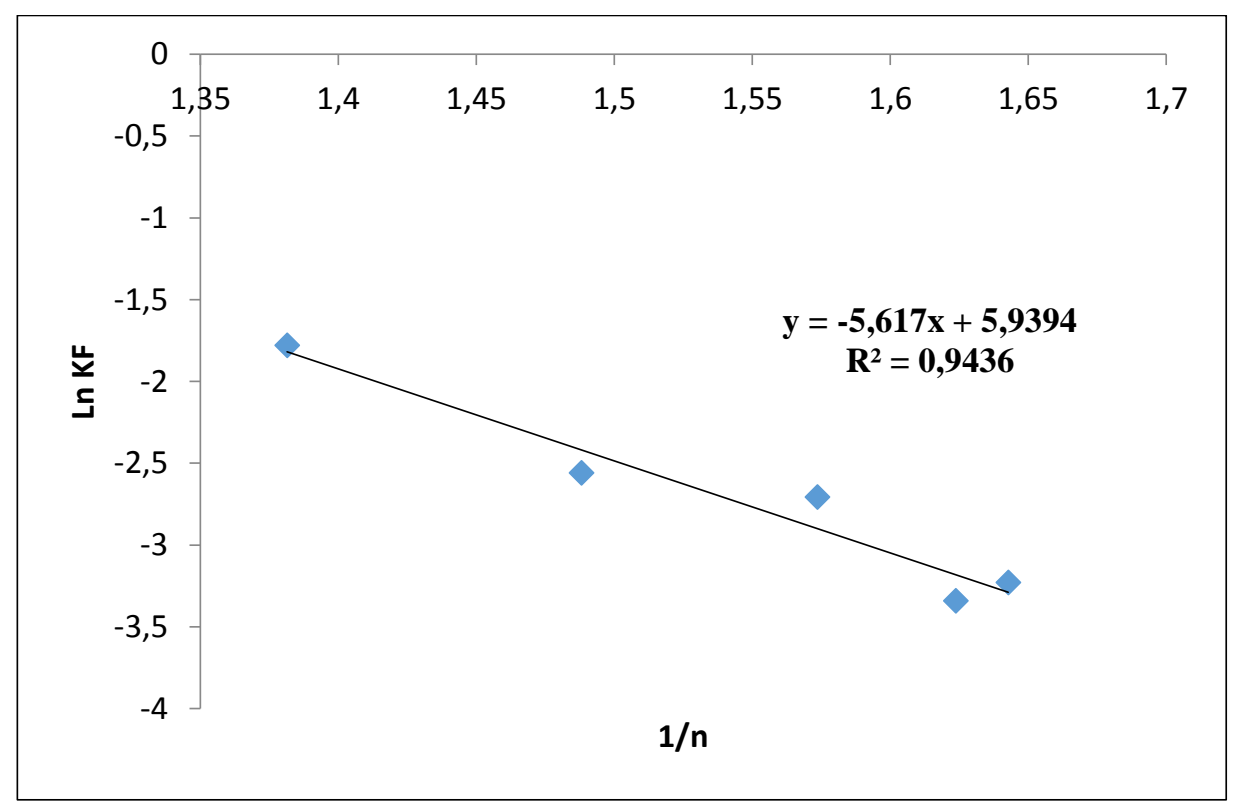

Figure 11. Application of the $\mathrm{LnK}_{\mathrm{F}}$ model according to $1 / \mathrm{n}$ for $\mathrm{B}-\mathrm{Al}_{13}$ 


\section{Determination of isosteric heat}

The isosteric heat of adsorption $\left(\Delta \mathrm{Hx}, \mathrm{kJ} \mathrm{mol}^{-1}\right)$ is defined as the heat of adsorption determined at a constant amount of the adsorbed compound. It presents one of the basic requirements for the characterization and optimization of an adsorption process. Knowing the heats of adsorption is very important for equipment and process design ${ }^{24}$.

$$
\begin{aligned}
& d\left(\operatorname{Ln} C_{e}\right)=-\frac{\Delta H_{x}}{R T^{2}} \times d T \\
& \operatorname{Ln} C_{e}=-\frac{\Delta H_{x}}{R T}+C
\end{aligned}
$$

Equation 10

Equation 11

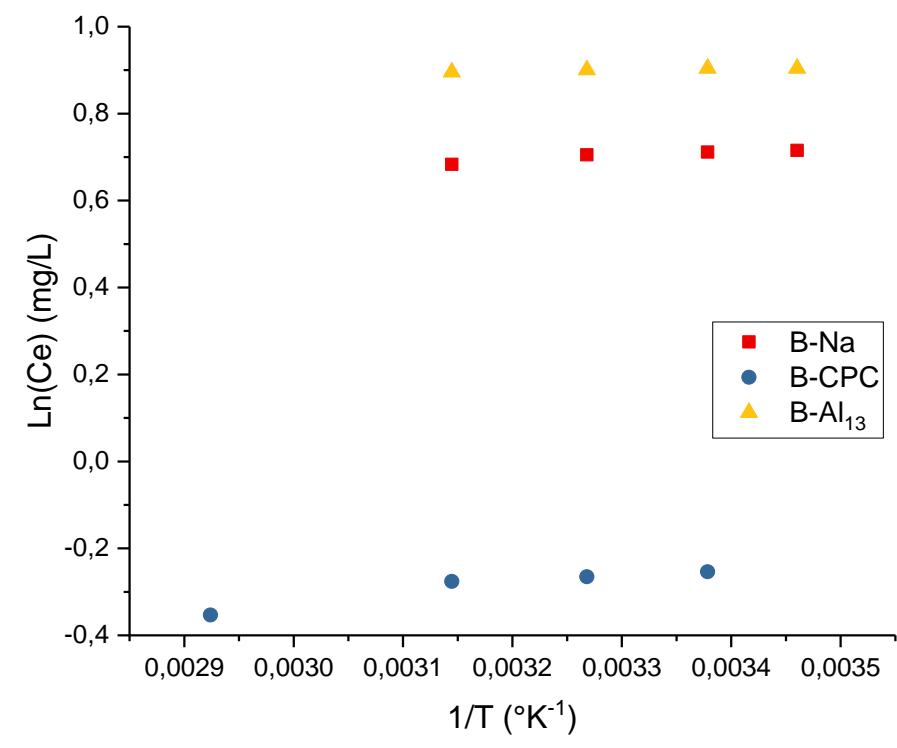

Figure 12. Determination of adsorption isosteric heat

For this purpose, the equilibrium concentration (Ce) at a constant amount of the adsorbate was obtained from isothermal data at different temperatures.

The values of $\Delta \mathrm{Hx}$ were obtained from the slope of the LnCe curve versus $1 / \mathrm{T}$ for different adsorbed quantities; the $\mathrm{LnCe}$ versus $1 / \mathrm{T}$ curves are linear (Figure 12).

The values of $\Delta \mathrm{Hx}$ were determined from the slope of the curves. The values of the $\mathrm{R}^{2}$ regression coefficients of the isosteric and the corresponding $\Delta \mathrm{Hx}$ values are listed in Table 3 .

For physical adsorption, the value of $\Delta \mathrm{Hx}$ should be less than $80 \mathrm{~kJ}$ mol-1, and for chemical adsorption, it varies between 80 and $400 \mathrm{~kJ} \mathrm{~mol}^{-1}$ according to $\mathrm{Mr}$ Dogan, and Mr Alkan 24, 25.

In the current system, the $\Delta \mathrm{Hx}$ values obtained are between 2 and $40 \mathrm{~kJ} \mathrm{~mol}^{-1}$, which indicates that the adsorption of thymol on the clays studied is dominated by a physical process involving Van der Walls interactions.

It is observed that the values of $\Delta \mathrm{Hx}$ are different according to the type of clay used. It is also found that the value of $\triangle \mathrm{Hx}$ in the case of $\mathrm{B}-\mathrm{CPC}$ is greater than that of $\mathrm{B}-\mathrm{Al}_{13}$ although the adsorbed amount in the case of $\mathrm{B}-\mathrm{Al}_{13}$ is higher than that of $\mathrm{BB}-\mathrm{CPC}$. This is due to the vast area of $\mathrm{B}-\mathrm{Al}_{13}$ compared to that of B-CPC.

The comparison of these results with the specific surface data shows that $\Delta \mathrm{Hx}$ decreases with the increase of the specific surface and increases with the heterogeneity of the surface (dispersion of the active sites). The variation of $\Delta \mathrm{Hx}$ may also be due to an adsorbate-adsorbate interaction followed by the adsorbate-adsorbent interaction.

The variation of $\Delta \mathrm{Hx}$ with the surface charge can also be attributed to the possibility of lateral interactions between the adsorbed thymol molecules.

Table 3. Thermodynamic models Constants.

\begin{tabular}{|c|c|c|c|}
\hline \multicolumn{3}{|c|}{ Rankine (Calendar) modified } \\
\hline Clays & $\mathbf{R}^{\mathbf{2}}$ & $\boldsymbol{\alpha}$ & $\boldsymbol{\beta}$ \\
\hline Sodium Clay (B-Na) & 0,9511 & 5,4134 & -1788 \\
\hline Pillared Clay (B-Al $\left.{ }_{13}\right)$ & 0,997 & 4,7779 & $-320,63$ \\
\hline Organophilic Clay (B-CPC) & 0,9886 & 2,0819 & $-1187,7$ \\
\hline
\end{tabular}




\begin{tabular}{|c|c|c|c|}
\hline \multicolumn{3}{|c|}{ Model of LnK versus 1/n } \\
\hline Clays & $\mathbf{R}^{\mathbf{2}}$ & $\boldsymbol{\alpha}$ & $\begin{array}{c}\text { The ordered } \\
\text { at the origin }\end{array}$ \\
\hline Sodium Clay (B-Na) & 0,9779 & $-5,5843$ & $-4,8287$ \\
\hline Pillared Clay (B-Al 13 ) & 0,9436 & 5,617 & 0,9436 \\
\hline Organophilic Clay (B-CPC) & 0,8739 & 4,3561 & 5,5546 \\
\hline Clays & The isosteric energies & & C \\
\hline Sodium Clay (B-Na) & $\mathbf{R}^{\mathbf{2}}$ & $\Delta \mathbf{H}_{\mathbf{x}}$ & 0,4762 \\
\hline Pillared Clay (B-Al 13 ) & 0,9543 & 8,6212 & 0,8375 \\
\hline Organophilic Clay (B-CPC) & 0,9432 & 2,4022 & $-1,2836$ \\
\hline
\end{tabular}

\section{Conclusion}

The constants of the thermodynamic models applied the increase in temperature in the range studied for the thymol, causes a decrease in the adsorption capacity of the adsorbates on the clay at equilibrium. This decrease means that the adsorption process of the adsorbates on the clays is spontaneous and exothermic.

Adsorption was a spontaneous, endothermic process. This was also supported by the thermodynamic parameters calculated at different temperatures. The isosteric heats of adsorption were calculated by applying the Clausius-Clapeyron equation. The isosteric heat of adsorption increased with increase in surface loading indicating that chemically modified bentonite is having energetically heterogeneous surface and there may be some lateral interactions between the thymol and surface.

\section{Acknowledgements}

The authors are sincerely thankful to MESRSFC and CNRST -Morocco for financial support of Project PPR 15-17, and Prof. Brahim Amanchar for reviewing all the text in order to correct the language mistakes.

\section{References}

1- S. Pandey, A comprehensive review of recent developments in bentonite-based materials used as adsorbents for wastewater treatment. Journal of Molecular Liquids, 2017, 241, 1091-1113.

2- S. Pandey, K. K, Nanda, Au nanocomposite based chemiresistive ammonia sensor for health monitoring. Journal of American Chemical Society Sensors, 2015, 1 (1), 55-62.

3- S. Pandey, S. B. Mishra, Chromatographic resolution of racemic $\alpha$-amino acids: Chiral stationary phase derived from modified xanthan gum. Journal of Carbohydrate polymers, 2013, 92 (2), 2201-2205.

4- S. Pandey, J. Ramontja, Sodium alginate stabilized silver nanoparticles-silica nanohybrid and their antibacterial characteristics. International journal of biological, 2016, 93, 712-723.

5- M. Diarmid, G. Alan, Synthetic metals: A novel role for organic polymers, Angewandte Chemie International Edition, 2001, 40 (14), 2581-2590.

6- V. C. Srivastava, I. D. Mall, I. M. Mishra, Adsorption thermodynamics and isosteric heat of adsorption of toxic metal ions onto bagasse fly ash (BFA) and rice husk ash (RHA). Journal of Chemical Engineering, 2007, 132, 267-278.

7- H. Li, M. Xu, Z. Shi, B. He, Isotherm analysis of phenol adsorption on polymeric adsorbents from nonaqueous solution. Journal of Colloid and Interface Science, 2004, 271 (1), 47-54.

8- B. J. Stanley, J. Krance, A. Roy, Determination of the thermodynamic contribution to peak asymmetry of basic solutes in reversed-phase liquid chromatography. Chromatography A, 1999, 865, 97-109.

9- P. Podkoscielny, A. Dabrowski, O.V. Marijuk, Heterogeneity of active carbons in adsorption of phenol aqueous solutions Journal of Applied Surface Science, 2003, 205, 297.

10- Z. Yaqiong, N. Yuge, L. Yangchao, G. Mei , Y. Tian, Y. Liangli, W. Qin, Fabrication, characterization and antimicrobial activities of thymol-loaded zein nanoparticles stabilized by sodium caseinate-chitosan hydrochloride double layer. Journal of Food Chemistry, 2014, 142, 269-275. 
11- M. Ramos, A. Jiménez, M. Peltzer, M. C. Garrigós, Development of novel nanobiocomposite antioxidant films based on poly (lactic acid) and thymol for active packaging. Journal of Food chemistry, 2014, 162, 149-155.

12- N. Jozja，P. Baillif，J. S. Touray，C. H. Pons, F. Muller, C. Burgevin, Impacts «multi-échelle » d'un échange ( $\mathrm{Mg}, \mathrm{Ca})-\mathrm{Pb}$ et ses conséquences sur l'augmentation de la perméabilité d'une bentonite. Comptes Rendus Géoscience, 2003, 335 (729-736).

13- C. C. Moreno, Adsorption of organic molecules from aqueous solutions on carbon materials. Journal of Carbon, 2004, 42 (1), 83-94.

14- V. P. Vinod, T.S. Anirudhan, effect of experimental variables on phenol adsorption on activated carbon prepared from coconut husk by single-step steam pyrolysis: masse transfer process and equilibrium studies. journal of scientific \& industrial research, 2002, 61, 129-138.

15- K.R. Srinivasan, H.S. Fogler, Use of inorganoorgano-clays in the removal of priority pollutants from industrial waste waters: Structural aspects. Journal of Clays \& Clay Minerals, 1990, 38, 277-286.

16- N. Platon, I. Sminiceanu, N.D. Miron, G. Muntianu, R.M. Zavada, G. Isopencu, D. Nistor, Preparation and Characterization of New Products Obtained by Pillaring Process. Revista de Chimie (Bucharest), 2011, 62, 799-805.

17- M. Elmiz, S. Salhi, I. Chraibi, A. El Bachiri, M. L. Fauconnier, A. Tahani, Characterization and adsorption study of thymol on pillared bentonite. Open Journal of Physical Chemistry, 2014, 4 (3), 98-116.

18- M. Elmiz, S. Salhi, A. El bachiri, J. P. Wathelet, A. Tahani, Adsorption study of tymol on Na-bentonite. Journal of Environmental Solutions, 2013, 2, 31-37.

19- M. Elmiz, K. Essifi, S. Salhi, F. Bergaya, A. Tahani, Synthesis and Characterization of CPC Organomodified and $\mathrm{Al}_{13}$ Pillared Modified Bentonite. Moroccan Journal of Chemistry, 2019, 7 (2), 242-253.

20- M. Djebbar, F. Djafri, M. Bouchekara and A. Djafri, Adsorption of phenol on natural clay. African Journal of Pure and Applied Chemistry, 2012, 6 (2), 15-25.

21- Y. Seki, K. Yurdakoç, Adsorption of Promethazine hydrochloride with KSF Montmorillonit. journal of Adsorption, 2006, 12 (1), 89-100.

22- V. C. Srivastava, M. M. Swamy, I. D. Mall, B. Prasad, I. M. Mishra, Adsorptive removal of phenol by bagasse fly ash and activated carbon: equilibrium, kinetics and thermodynamics,. journal of Colloids surfaces a: physicochemical engineering aspects, 2006, 272 (1-2), 89-104.

23- K. Urano, Y. Koichi, Y. Nakazawa, Equilibria for Adsorption of Organic Compounds on Activated Carbons in Aqueous Solutions . Modified Freundlich Isotherm Equation and Adsorption Potentials of Organic Compounds. Journal of Colloid and Interface Science, 1981, 81, 477-485.

24- C. Shamik, M. Rahul, S. Papita, K. Praveen, Adsorption thermodynamics, kinetics and isosteric heat of adsorption of malachite green onto chemically modified rice husk. journal of Desalination, 2011, 265, 159-168.

25- M. Doğan, M. Alkan, Removal of methyl violet from aqueous solution by perlite. Journal of Colloidal Interface Science, 2003, 267 (1), 32-41. 